\title{
Regional Economic Integration and Productivity Convergence: Empirical Evidence from East Asia
}

\section{Maryam Ishaq*}

\begin{abstract}
The study attempts to seek evidence on regional economic integration in driving labor productivity convergence in low- and middle-income East Asian states towards Japan, the country assumed to be the regional technology leader. The labor productivity convergence of low- and middle-income East Asian countries towards their rich neighbor is modelled against their national levels of innovation, technology spill-overs from the regional economic leader and their productivity differential with the frontier country. The hypothesized relationship is empirically verified for seven East Asian states, using a robust econometric approach. The time-series test estimates under Error Correction Representation yield absolute support in favor of valid productivity convergence occurring between Japan and its low-and middle income neighbors. However, panel data estimates generated with better statistical power outperform the time-series test findings and these results reject the significance of Japan as the regional productivity growth driver for its regional developing states.
\end{abstract}

Keywords: Regional economic integration, productivity convergence, growth spill-over, time-series error correction model, panel cointegration estimators

\section{JEL Classification: E24, F15.}

\section{Introduction}

The region of East Asia has seen unprecedented growth rates over the last four decades. Episodes of financial crisis, such as that which erupted in 1997-98 temporary slowed regional economic growth. After this crisis, not only did the high- and average- income regional states recover speedily but also those with low income levels overcame this financial set back with considerable speed, showing sustained rates of economic growth in the post-crisis period. Low-income countries like Cambodia, Lao Republic and Vietnam outpaced their pre-crisis growth performance in the

\footnotetext{
* Assistant Professor of Economics, The University of Lahore, Lahore, Pakistan.
} 
post-crisis period (IMF, 2007). A number of studies attribute this region wide post-crisis financial stability towards the heightened intra-regional trade and investment linkages, primarily carried out under the economic cooperation agreement of ASEAN and various other multilateral agreements (Fukuda \& Toya, 1995; Hsiao \& Hsiao, 2004; Mutaqin \& Ichihashi, 2012; Solarin et al., 2014).

The proponents of regional economic integration advocate enhanced economic linkages for regions where there are sharp income differences across member states. With the prospect of spillover effects of technology transfer, economic integration through trade, capital exchange and labor migration between developed and developing neighbor states is found to serve as a growth driver at the regional level. Presumably, such economic connections tend to bridge the income disparities amongst the neighbor countries, besides benefitting poorer states with the growth inducing effects of technological advancements and research and development taking place in developed countries. For a set of 24 advanced and developing economies, Coe and Helpman (1995) and Coe at al. (2009) establish significant and measurable impacts of domestic and foreign research and development (R\&D) capital stocks for total factor productivity (TFP) growth in catchingup countries. Griffith et al. (2004) investigate the (presumed) role of R\&D in enhancing technology transfer for a set of 12 OECD member states and find R\&D to be a statistically signficiant determinant in the catch-up process as well as in the direct stimulation of innovation. Cameron (2005) finds significant connections between technology transfer (from the U.S.) and TFP for manufacturing sector industries in the UK. For Turkish manufacturing firms, a positive long-run association between total factor and labor productivity is found by Yasar and Morrison (2008), which is induced by foreign direct investment, exports and imports. Xu (2000) investigates U.S. multinational enterprises (MNEs) as a channel of international technology diffusion in 40 countries and finds that the technology transfer provided by them significantly contributes to productivity growth in developed countries, though not in less developed ones. This is because a country needs to reach a minimum human capital threshold level in order to benefit from said technology transfer, and most less developed economies do not meet this requirement.

In this study, we investigate the role of developed East Asian economies In the growth of national productivity in developing regional economies. Considering Japan as the regional economic leader, we aim to verify the country's research and development spillover effects in inducing productivity (income) convergence to low income countries of East Asia. 
A vast number of studies have empirically verified the role of labor productivity growth in determining the trend patterns of a country's economic performance. During the last two and half decades, the high income states of the region have shown tremendous growth in their national per worker productivity levels. Before the period of 1990s, Japan's average labor productivity level was substantially higher than its neighbor states. However, in the early 1990s, Hong Kong and Singapore caught up and outpaced Japan in their national levels of average labor productivity. Starting in 2000, Singapore overtook both Japan and Hong Kong with national labor productivity levels of 75.6 percent, 90.2 percent and 92 percent (with 2010 as reference year) during the years 2000, 2009 and 2011, respectively (Asian Productivity Organization, 2013).

Nevertheless, the impressive rates of labor productivity catch up in East Asia is only evident for high income regional states. Looking at the middle and lower tier countries, their national labor productivity levels remained alarmingly low, relative to Japan, Hong Kong and Singapore despite their visible growth performance,. The three classic examples are Indonesia, Philippines and Thailand: With 2010 as the base year, the three countries report growth in per worker productivity levels of 2.5 to 9.5 percent, 6.8 to 9.2 percent and 3.6 to 15.4 percent (respectively) for the years 1970 to 2011. These statistics for low-income East Asian states not only reflect serious stagnation in their national labor productivity levels but also highlight their overwhelmingly large gaps relative to the above referred high-income neighboring economies.

\section{Literature Review}

A primary impetus in establishing regional economic linkages between countries is to reduce income disparities and encourage inclusive growth, so that the benefits of enhanced economic relationships could be reaped by all. Owing to the importance of outward orientation (i.e., openness to trade and foreign direct investment), and human capital investment, Lim and MacAleer (2000) conduct a robust econometric analysis to investigate the degree of output convergence and technology catch-up for South East Asian countries amongst each other and also with U.S. The study finds no concrete evidence in support of significant productivity convergence of the ASEAN-5 countries twith the technology leaders i.e., United States as well as High Performing Asian Economies (HPAEs). For a group of ten East Asian economies, Zhang (2001) attempts to establish a connection between income convergence, regional trade and FDI flows but finds no significant association between the variables. Joian (2002) under the theoretical 
predictions of neoclassical growth models shows that there remain sharp income disparities between high and low-income East Asian countries. Similarly, Michelis and Neaime (2004) obtain partial support in favor of real per capita GDP convergence amongst APEC -17 countries and East Asian countries; rather, income divergence is empirically evident in the case of ASEAN countries.

Mahmood and Afza (2008) reveal two interesting observations on East Asian total factor productivity (TFP) growth dynamics. (i) region-wide TFP growth is primarily driven by technology improvements at the country level, rather than improvement in production efficiency or any other factor, and (ii) trade openness and foreign direct investment are not found to be significant determinants of TFP growth and its components.

Franks et al. (2018) examine the extent of economic integration taking place in the European Union (EU) region across multiple dimensions of the macroeconomy. Their results reveal that since the adoption of the common currency, nominal convergence of inflation and interest rates has taken place. Nevertheless, real convergence in the form of real per capita income has been negligible. This is particularly true for original euro area member states, where income convergence remained stagnant during the early years and turned into divergence in the times of global financial crisis. The study advocates adoption of measures effective for boosting productivity growth in lagging countries, so that income convergence at an at least modest rate might be ensured. Grabner et al. (2019) reveal the significance of countryspecific characteristics for understanding how economic and financial openness to shocks cause path-dependent development trajectories in the context of European integration, confirming the lack of a sufficient degree of convergence. The non-convergence is more pronounced in terms of technological capabilities, which otherwise are expected to serve as key for determining future development paths of the regions.

Considering the studies cited above, it appears that findings of deficient convergence is common when convergence is measured using national aggregates. In contrast, a few recent studies investigating the convergence patterns of real output and technical efficiencies at sectoral/industry level yield more encouraging results. Studying the magnitude of convergence in technical efficiency and productivity levels of the health care systems of twenty-six EU members, Kasman et al. (2019) find valid convergence for sample countries. Measuring technical efficiency scores for the health care systems through DEA, a non-parametric production frontier approach, and productivity through TFP, their estimates 
(acquired through both and convergence measures) confirm significant existence of cross-country sectoral (health care) convergence in terms of technical efficiency as well as productivity. In gauging the degree of economic integration for the corporate sector of the U.S. and the European states, Valsan and Druica (2020) test convergence in terms of economic performance, institutional arrangements, and market valuation along industry lines. They conduct an industry-driven cluster analysis, relying on six measures of economic coherency pertaining to operating performance, ownership, and market valuation and find European candidates better at persuing convergence (relative to the U.S.), yielding clusters with higher degree of stability.

Given the considerably sluggish labor productivity growth performance of low-income East Asian countries, it is of critical importance to investigate which of macroeconomic factors can (potentially) boost the productivity (income) convergence of the poorer states towards their richer counterparts. Focusing such factors in the perview of macroeconomic policy actions may facilitate the lower tier East Asian economies in their efforts to catch up their high income neighbors.

\section{Theoretical Framework}

The world economy is comprised of two countries only, $i \in(1,2)$. Each country produces $\mathrm{n}$ number of differentiated commodities $\left(p_{i}\right), i=$ $1, \cdots \cdots \cdots, n$. For both countries, production patterns are analogous to the neoclassical production function:

$$
\begin{aligned}
& Q_{i t}=A_{i t} F\left(L_{i t}, K_{i t}\right) \\
& Q=\text { National output }
\end{aligned}
$$

$A=$ Index of technical efficiency - the part of output unexplained by labor and capital, also known as TFP. A may vary across countries.

$L=$ Employed labor

$K=$ Capital stocks

Function $F$ is linearly homogenous and is subject to diminishing marginal returns to the stocks of both labor and capital.

It is assumed that at time $t$, one of the two countries $i$ will outperform the other in terms of productivity growth. This country is titled 
as the technological frontier and is symbolized by $F$. The other country, lagging behind the frontier country, is indexed by $H$. For this study, Japan will serve as the frontier country $(F)$ and rest of the East Asian states (individually) are taken as its less developed counterparts $(H)$.

Bernard and Jones (1996a, 1996b), Cameron et al., (2005) and Kutan and Yigit (2009) prescribe the following patterns of productivity growth in country $H$, induced by domestic innovation and technology spillovers from the frontier economy,

$$
q_{H t}=\vartheta_{H}+\rho_{H}\left(\frac{q_{F t-1}}{q_{H t-1}}\right), \quad \vartheta, \rho \geq 0
$$

$\vartheta_{H}=$ measure of domestic (country-specific) rate of innovation in the less developed country $(H)$

$\rho_{H}=$ measure of technology transfer from country $F$ to country $H$

The small letters are representative of the fact that model variables are subject to logarithmic transformation. In equation (2), $\left(\frac{q_{F t-1}}{q_{H t-1}}\right)$ is the distance variable ${ }^{1}$, parameterizing the rate of technology transfer from country $F$ to country $H$. Productivity convergence, induced by the technology transfer from country $F$ to country $H$, of each less developed East Asian state is directly determined by the size of this distance variable. The farther the country $H$ lies from country $F$, the larger is the productivity differential between the two countries. Resultantly, the ratio (of productivity of $H$ to that of $F$ ) becomes smaller, yielding larger value on part of distance variable (where the series is considered in absolute form).

Equation (2) holds valid for less developed East Asian states only. For the frontier country, the sole source of productivity growth is its time varying levels of domestic innovations. Accordingly, the productivity growth patterns for frontier country $(F)$ can be given as:

$$
q_{F}=\vartheta_{F}, \quad \vartheta \geq 0
$$

Where $\vartheta_{F}$ is the measure of domestic (country-specific) rate of innovation in the frontier country $(F)$.

\footnotetext{
${ }^{1}$ Whilst estimating the model empirically, the distance variable will be measured by the absolute of natural logarithmic ratio of productivity of each East Asian country to the productivity of Japan.
} 
To see the trend movements of relative productivity of country $F$ and country $H$, as determined by domestic levels of innovation and cross-country technological transfers, equation (2) and (3) are combined as follows:

$$
\frac{q_{H t}}{q_{F t}}=\left(\vartheta_{H}-\vartheta_{F}\right)-\rho_{H}\left(\frac{q_{H t-1}}{q_{F t-1}}\right),
$$

For the purpose of estimating the proposed model empirically, equation (2) will be tested under the Error Correction (EC) representation of productivity growth. The EC process will model the self-induced corrections of relative productivity (between country $H$ and country $F$ ) movements, making the series converge to its long-run or steady-state levels. The steady-state or long-run equilibrium level of relative productivity series necessitates that the productivity of country $H$ should lag an equilibrium distance behind its counterpart in the frontier country. Only then, the productivity growth in country $H$, induced by domestic innovation and technology transfer from country $F$, can be exactly equal to productivity growth in country $F$, induced by country's domestic levels of innovation. Mathematically, this condition of steady-state relative productivity between two countries is analogous to $\frac{q_{H}^{*}}{q_{F}^{*}}<0<=>\vartheta_{F}>\vartheta_{H}$. Thus, from equation (4), the above discussed steady-state or (long-run) equilibrium level of relative productivity $\left(\tilde{q}^{*}\right)$ between country $H$ and country $F$ can be obtained as follows:

$$
\tilde{q}^{*} \equiv \frac{q_{H}^{*}}{q_{F}^{*}}=\frac{\vartheta_{H}-\vartheta_{F}}{\rho_{H}}
$$

Where

$q_{H}^{*}=$ Steady-state level of country $H^{\prime}$ s productivity

$q_{F}^{*}=$ Steady-state level of country $F^{\prime}$ s productivity

Equation (5) implies that steady state level of relative productivity between country $H$ and country $F$ is a function of their domestic innovation differential (gap) and the rate of technology transfer from country $F$ to country $H$.

Until now, $\vartheta_{i}$ is used to parameterize the domestic innovation level at country $H$ and $F$. Nevertheless, a vast amount of theoretical and empirical literature attributes the domestic innovation levels of a country to the levels of its R\&D. It is also evident from literature that R\&D levels 
enhance the "absorptive capacity", hence, can be a potential determinant of technology transfer from more developed to less developed countries. Theoretical and empirical literature on endogenous growth models also raise the importance of international trade (exports and imports more prominently) and human capital in triggering innovation and/or technology transfer effects whilst explaining trend growth patterns of economies (Aghion et al., 1998; Ben-David \& Loewy, 1998; Griliches \& Litchnberg, 1984; Lawrence \& Weinstein, 2001). It is thus legitimate to model both domestic innovation $\left(\vartheta_{i}\right)$ of country $H$ and technology transfer $\left(\rho_{H}\right)$ from country $F$ to country $H$ against country $H$ 's R\&D, international trade, and the levels of human capital:

$$
\begin{gathered}
\vartheta_{H t}=\mu_{H}+\gamma X_{H t} \\
\rho_{H}=\delta+\tau X_{H t}
\end{gathered}
$$

Where $X$ measures $R \& D$, international trade, and human capital. Incorporating equation (6A) and (6B) into equation (2), the (econometrically) long-run estimable version of our productivity convergence model for less developed country $(H)$ is given as:

$$
q_{H t}=\mu_{H}+\gamma X_{i t-1}+\delta\left(\frac{q_{F t-1}}{q_{H t-1}}\right)+\tau X_{i t-1} \cdot\left(\frac{q_{F t-1}}{q_{H t-1}}\right)+\varepsilon_{t}
$$

From equation (7), the level term $\left(\gamma X_{i t-1}\right)$ captures the direct relationship between country $H$ 's $R \& D$, international trade, and human capital with its productivity through domestic innovation. On the other hand, the interaction term $\left(\tau X_{i t-1} \cdot\left(\frac{q_{F t-1}}{q_{H t-1}}\right)\right)$ establishes the same above stated linkage through technology transfer from country $F$ to country $H$. It is noticeable that the model suggests heterogeneous or country-specific levels of domestic innovation and technology transfer, conditional upon national $\mathrm{R} \& \mathrm{D}$, international trade, and human capital levels.

\section{Empirical Estimation Framework}

The rate of productivity convergence induced by domestic innovation levels and technology transfer from the frontier country to less developed states of East Asia is measured through the Error Correction Model (ECM), using a Newey-West (NW) HAC OLS estimator. A number of cointegration-based methods are suggested by related studies for empirically verifying the phenomenon of convergence (Aubyn, 1999; Giles, 2005; Lluís Carrion-I-Silvestre \& German-Soto, 2007). Among these, the class 
of residual-based cointegration tests hold a special place, being simple in computation with straightforward interpretations using economic theory. Under the residual-based cointegration approach, the existence of cointegration between two or more time-series implies that they have a meaningful association: It is this association which prevents the residuals from becoming larger and larger in the long-run. The model estimates the speed of adjustment of regressors from short-run disequilibrium to long-run equilibrium. The lagged residuals from equation (7) (in static form) will be modelled against $q_{H t}$ (along with lagged values of model parameters) under a dynamic representation. In the context of productivity convergence dynamics (proposed in equation (7)), the error correction process (if statistically significant) estimates the speed of convergence/correction made by $q_{H t}$ from its short-run misalignments to converge to a long-run equilibrium (steady-state), through its own periodic movements as well as the periodic movements of other model parameters.

Like any other conventional cointegration model, the ECM is equally efficient in capturing the plausible presence of long-run association between variables, if there exists any. According to the Granger representation theorem, if $q_{H t}$ and the model determinants (of equation (7)) are cointegrated, only then, there will exist a valid error correction process relating these variables and vice versa.

The long-run regression given in equation (7) may be used in the following ECM, with the remaining parameters being consistently estimated by the NW HAC OLS estimator.

$$
\begin{aligned}
q_{H t}= & \mu_{H}^{\prime}+\sigma\left[q_{H t-1}-\gamma X_{i t-1}-\delta\left(\frac{q_{F t-1}}{q_{H t-1}}\right)-\tau X_{i t-1} \cdot\left(\frac{q_{F t-1}}{q_{H t-1}}\right)\right]_{t-1}+ \\
& \sum_{j=1}^{m} \Delta q_{H t-j} \sum_{j=0}^{k} \Delta \gamma^{\prime} X_{i t-j}+\sum_{j=0}^{k} \Delta \tau^{\prime} X_{i t-j} \cdot\left(\frac{q_{F t-1}}{q_{H t-1}}\right)+\varepsilon_{t}^{\prime},
\end{aligned}
$$

In equation (8), the augmented version of the ECM is established, where difference-lagged terms of $q_{H t}$ and explanatory variables are allowed to contribute to the short run dynamics of the model. Note that a valid error correction (convergence towards long-run steady-state) process necessitates that the estimated coefficient $\rho$ in the ECM equation (8) should bear a negative sign $(\hat{\sigma}<0)$ and be statistically significant.

Once a statistically significant error correction process is established, a cointegration regression estimator can be used to obtain long-run slope coefficients of model variables. For this purpose, the study employs Fully Modified OLS (FMOLS), devised by Phillips and Hansen (1990). FMOLS is 
shown to perform better in small samples. The usefulness of the estimator can be gauged from its ability to correct for endogenity bias and serial correlation using a semi-parametric regression, thus allowing for standard normal inference. The test can identify long-run parameters from static level regressions when the variables are first-order integrated.

\section{Data Description and Sample Countries}

For estimating the model parameters in equation (8), the data is taken primarily from (a) World Development Indicators (WDI) database, (b) United Nations Educational, Scientific and Cultural Organization (UNESCO) Statistical Year Book (statistical tables), and (c) United Nations Conference on Trade and Development (UNCTAD). The sample period varies from country to country, ranging from 1980 to 2017 and sample countries including China, Hong Kong2, Korea, Malaysia, the Philippines, Singapore, and Thailand as less developed neighbor economies of Japan, serving as the developed frontier country of the region. As per the definition of WDI and UNESCO Statistical Year Book, the model variables ${ }^{3}$ can be described as follows.

i. National Productivity: This is the model regressand (with its lagged values and its ratio with its counterpart in frontier country (the distance variable) serve as model explanatory variables). It is measured as the average annual productivity of labor (Baumol, 1986; Kang and Peng, 2018; Quintana-Romero et al., 2019) and formulated as GDP at constant market prices (2010) from WDI as a ratio of the total employed labor force of the country taken from UNCTAD.

ii. National Rate of Innovation: For this study, rate of innovation (one of the model regressors) in less developed East Asian counties is analogous to country's annual $R \& D$ expenditures. The variable is measured through annual expenditures on $R \& D$ as a percentage of that year's GNP, sourced from UNESCO Statistical Year Book. This follows a number of studies measuring technological growth similarly (Cameron et al., 2005; Cincera, 2005; Terleckyj, 1980; Zachariadis, 2003;).

iii. National Levels of Human Capital Formation: Following Schultz (1960), Khaemba (2014) and de Pleijt, (2018), this 1 explanatory variable is measured through the total (annual) number of secondary education

\footnotetext{
${ }^{2}$ For Hong Kong and Malaysia, the sample data period ranges from 1996 to 2017. For China, the sample data set is for 1987 to 2017.

${ }^{3}$ The variables are used for model estimation after undergoing a natural logarithmic transformation.
} 
pupils enrolled in public and private schools and colleges. The series is taken from the WDI database.

iv. National Levels of Net Exports: This is another model regressor accounting for the degree of openness of the home country towards international goods and services market. The variable is composed of the difference between country's total annual exports and imports measured at 2010 constant market prices. The export and import series are taken from the WDI database.

\section{Results for Individual Country Analysis}

Before discussing our main estimations, we estimate a correlation matrix of residuals and model regressors of equation (7), the model regressors being an obvious suspect for introducing endogenity bias. This is particularly true for international trade, in the context of the tradegrowth connection. Existing literature has paid much attention to detecting and dealing with the problem of endogenity (Cameron et al., 2005; Kutan \& Yigit, 2009). A strong covariance (correlation) between model regressors and the residuals of equation (7) can be taken as an evidence in support of plausible presence of endogenity in regressors (Wooldridge, 2015).

From the estimated correlation matrix, a correlation coefficient of value of 1 or -1 (or sufficiently far from zero) will be taken as an evidence in favor of significant endogenity bias in the explanatory variables, and vice versa.

\section{Table 1: Correlation Matrix of Residuals from Equation (7) and Model Regressors}

\begin{tabular}{lccccccc}
\hline & $\hat{\varepsilon}$ & $\hat{\varepsilon}$ & $\hat{\varepsilon}$ & $\hat{\varepsilon}$ & $\hat{\varepsilon}$ & $\hat{\varepsilon}$ & $\hat{\varepsilon}$ \\
& Hong Kong & China & Korea & Malaysia & Philippines & Singapore & Thailand \\
\hline Residuals $(\hat{\varepsilon})$ & 1.00 & 1.00 & 1.00 & 1.00 & 1.00 & 1.00 & 1.00 \\
R\&D & 0.00 & -0.02 & -0.25 & -0.02 & -0.01 & -0.19 & -0.01 \\
Human Capital & 0.01 & -0.06 & 0.02 & -0.07 & -0.16 & -0.11 & -0.15 \\
International Trade & -0.04 & -0.05 & -0.51 & -0.01 & -0.09 & 0.09 & -0.23 \\
Productivity Differential & 0.01 & -0.03 & -0.40 & 0.02 & 0.02 & -0.09 & -0.10 \\
\hline
\end{tabular}

Notes: (i) All the model variables of equation (7) are integrated of order one, as proven by DF-GLS unit root test. (ii) are the residuals obtained from estimating equation (7) (in first differenced form) through Newey-West HAC OLS regression.

(iii) Other than, all the variables in matrix are considered in first-differenced form.

The estimated correlation coefficients are reported in Table 1. One sees that for all model regressors, the value of the correlation coefficient is close to zero. Even for those cases where the coefficient value significantly 
deviates from zero (i.e., Korean international trade (-0.51) and its productivity differential against Japan (-0.40)) it is still not sufficiently close to -1 (or 1). These findings militate against the presence of endogenity bias in the model regressors, which potentially could prevent us from estimating the subject relationship under a single equation error correction representation. Thus, there is enough statistical evidence to legitimately estimate equation (7) with the ECM, which necessitates weak exogeneity of regressors.

Estimates from equation (8) are reported in Table 2. Error correction coefficients, accounting for productivity convergence towards steady-state long-run equilibrium levels, are reported for each individual country 4 . The subsequent long-run coefficients of the model's parameters, estimated through FMOLS cointegration regression estimators, are also given in the same table.

Before discussing the two types of estimates and the associated inferences, it is worth noting that (a) all of the five sample countries display statistically significant productivity convergence processes towards longrun equilibrium, and (b) initially, the model is estimated with level variables only, with no interaction terms involved. However, for the second specification, an augmented version of the model is estimated, by incorporating the interaction terms, primarily responsible for measuring technology transfer from the frontier (Japan) economy to less developed East Asian states. For example, in case of Korea, column KI reports FMOLS test estimates (against equation (8)) with level variables only but column K2 holds estimates for the augmented version of equation (8).

China, Korea, Philippines, Singapore and Thailand all generate valid $(\hat{\sigma}<0)$ and statistically significant error correction coefficients. For the set of sample countries, the speed of convergence ranges from -0.69 (Thailand) to -2.04 (Singapore). A valid and significant error correction coefficient provides support for a regional convergence process. In the short-run, while productivity departs from its steady state, the series still trends in such a way that it self-adjusts (in each period) towards the longrun steady state (corrections) against those misalignments (errors) which are responsible for keeping it away from its long-run equilibrium. This process of error(s) correction is significantly supported by the lagged values of all model parameters. Thus, on the whole, the periodic

\footnotetext{
${ }^{4}$ ECM is not estimated for Hong Kong and Malaysia due to small size of available sample data for
} these two countries. 
productivity movements of less developed East Asian countries display a valid and significant tendency of attaining their long run equilibrium levels, as explained by their productivity differential with Japan, domestic innovation level and the rate of technology transfer from Japan. These results are in sharp contrast with earlier empirical work conducted on the region, which found inconsequential the role of world as well as regional technology leaders for in bringing income or output convergence for poorer East Asian states (Lim \& MacAleer, 2000; Xu, 2000; Zhang, 2001; Joian, 2002). Such a disparity might be (largely) attributed to the sample study period employed under previous studies, primarily comprising preGlobal Financial Crisis (GFC) period. Nevertheless, it is evident that the catch up potential for low-income Asian countries evolved at a very pronounced pace in post-GFC years (Asian Development Outlook, 2016; Michelis \& Neaime, 2004).

Having established the validity of error correction process, let us now evaluate the individual contribution of each of the model parameters towards productivity movements through the FMOLS cointegration regression estimator, using the model given in equation (8). As stated above, the model is estimated under both its unaugmented (with level terms only) as well as augmented (with level plus interaction terms) version.

Beginning with the productivity differential, it imparts a positive and statistically significant convergence effect on the productivity of subject East Asian states (except Singapore). For China, Korea, the Philippines, and Thailand, the long-run coefficient on the productivity differential ranges from 0.40 to 0.63 . This magnitude is largest for the Philippines, which had the largest initial productivity gap with Japan. However, upon the inclusion of interaction terms, the productivity differential tends to lose its statisitical significance in determining the domestic long-run productivity movements. This is particularly true for China and Korea. For the Philippines and Singapore, the productivity differential, while remaining statistically significant as a determinant of long-run productivity, counterintuitively becomes negative. These findings are in line with those of Kutan and Yigit (2009). 


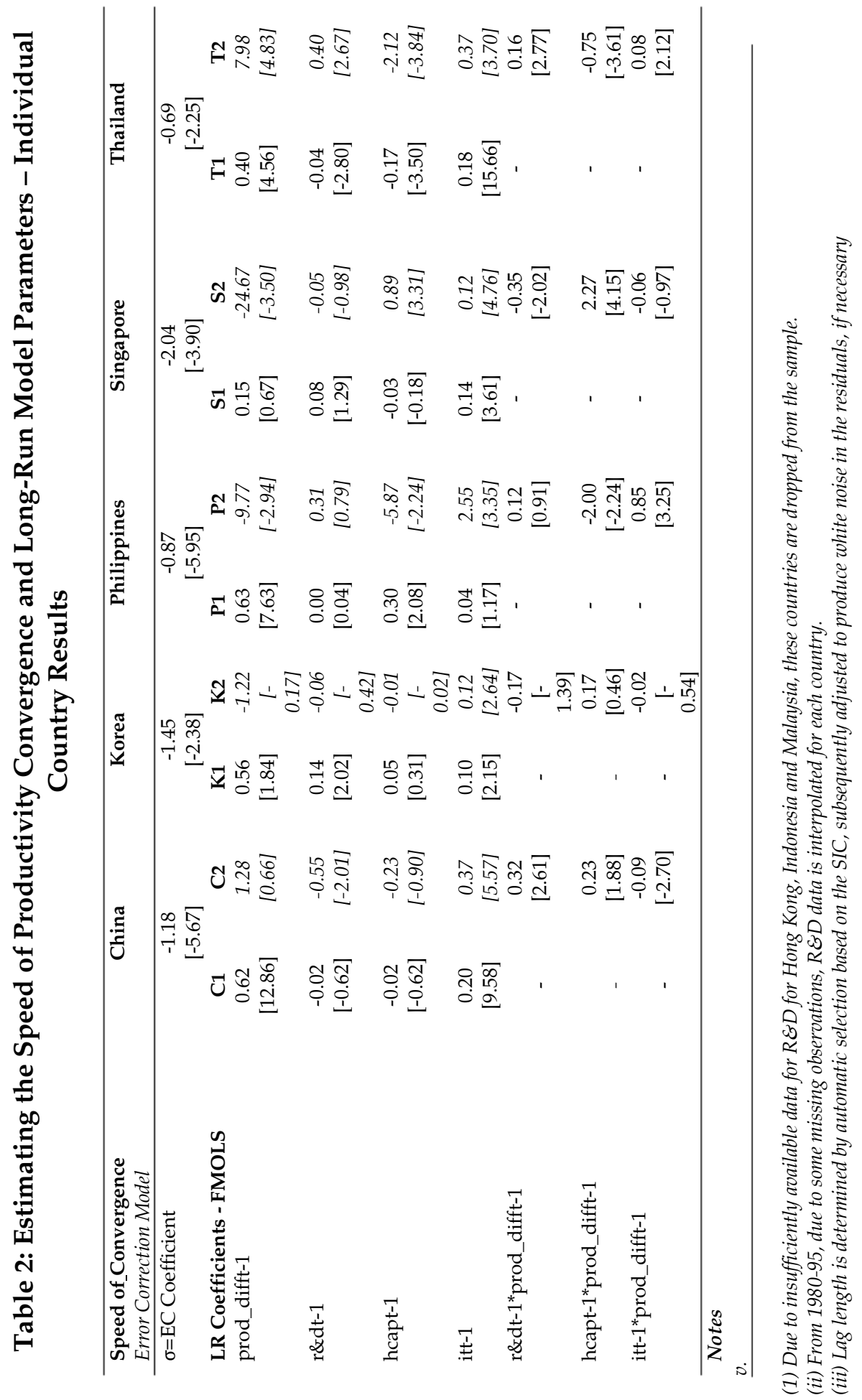


Next, looking into the determinants of domestic innovation i.e., national R\&D expenditures and human capital formation, these variables have had mixed effects on the long-run productivity patterns of the subject economies. Only for Korea do R\&D expenditures carry a positive long-run coefficient. For China, Philippines and Singapore, this effect is statistically insignificant, whereas for Thailand, country's R\&D expenditures tend to impart negative effects on domestic productivity levels. Human capital formation, measured as secondary school enrollments, is largely found to have either a negative or statistically insignificant long-run association with productivity (except Philippines). For Singapore, positive and statistically significant coefficients are also obtained, but that only with the inclusion of interaction terms into the model.

Finally, we consider the role of international trade, the variable responsible for channelling technology growth from the frontier economy to subject countries. This series maintains a positive and statistically significant long-run relationship with productivity. Our estimates on the role of international trade conform to the findings of Michelis and Neaime (2004) and Zhang (2001). Either in level form or with interaction terms, the variable in almost all cases imparts a positive long-run effect on productivity for all sample states, with a slope coefficient of value ranging from 0.04 to 1.71. Nevertheless, the case of Philippines (without interaction terms) is an exception.

\section{Evidence from Panel Data Estimates}

Panel data analysis has a potential advantage over the analysis of individual country data because it allows the pooling of data, providing better statistical power. Most time-series suffer from the problem of small numbers of observations. This issue results in insignificant $\mathrm{t}$-ratios or Fstatistics, raising concerns about the validity and power of both short-run and long-run estimates. This issue is common in annual data studies where it is rare to find economic data series covering more than fifty years. In this respect, panel data estimation methods are preferred since data series can be pooled into panels of different countries.

Here we seek evidence on productivity convergence in East Asian states by estimating a Panel Error Correction Model (PECM). We employ Westerlund's (2007) error correction approach to long-run cointegration for unbalanced panels. Unlike the conventional residual-based time-series and panel error correction representations, Wasterlund's model encompasses structural rather than residual-based dynamics. This saves 
his model from the complexity of common-factor restrictions, a feature inherent to conventional residual based tests, whose failure can cause a significant loss of power for residual-based cointegration models. Under the conditional error correction representation, Wasterlund's model tests the null of no valid cointegration between model variables by inferring if the error correction coefficient is zero. This test holds a meaningful application for our proposed model of productivity convergence owing to the following reasons: (a) heterogeneity amongst panels is admissible to a fairly large extent, both in long-run cointegration vectors and short-run model dynamics and, (b) the test is fairly robust against cross-sectional dependence, an issue common to other panel cointegration estimators. Wasterlund's PECM comprises four newly developed panel cointegration estimators, which follow a normal distribution, and are efficient enough to control for unit-specific short-run to long-run dynamics, unit specific slope and trend parameters, and cross-sectional dependence. The model follows the following data generating process:

$$
\begin{aligned}
q_{H i, t}= & \mu_{H i}^{\prime} d_{t}+\varphi\left[q_{H i, t-1}-\gamma_{i} X_{H i, t-1}-\delta_{i}\left(\frac{q_{F t-1}}{q_{H t-1}}\right)-\right. \\
& \left.\tau_{i} X_{H i, t-1} \cdot\left(\frac{q_{F t-1}}{q_{H i, t-1}}\right)\right]_{t-1}+\sum_{j=1}^{m i} \Delta q_{H i, t-j} \sum_{j=-q t}^{p i} \Delta \gamma_{i}^{\prime} X_{i, t-j}+ \\
& \sum_{j=-q t}^{p i} \Delta \tau_{i}^{\prime} X_{i, t-j} \cdot\left(\frac{q_{F t-1}}{q_{H i, t-1}}\right)+\varepsilon_{t}^{\prime}
\end{aligned}
$$

In Equation (9), the time-series and cross-sectional units are indexed $t=1, \ldots \ldots \ldots, T$ and $i=1, \ldots \ldots \ldots, N$, respectively. $\mu^{\prime}$ is the heterogeneous constant term and $d_{t}$ constitutes the deterministic component. All the model regressors are assumed to be a pure random walk in levels, and absolutely mean reverting in first differences. $\varphi$ is the speed coefficient of adjustment/correction the system makes towards long-run equilibrium, after a short-run fluctuation. The null hypothesis of no cointegration between $q_{H i}$ with model regressors is analogous to $\varphi_{i}=0$ (Persyn \& Westerlund, 2008). The alternative hypothesis of valid error correction process necessitates that $\varphi_{i}<0$ i.e., a statistically valid convergence of the system towards long-run equilibrium. The coefficient value of $\varphi_{i}$ is also critical for the occurrence of alternative hypothesis. Two of four tests, called the panel tests, assumes the homogeneity of $\varphi_{i}$ for all $i$ i.e., $H_{1}=\varphi_{i}=\varphi<0$ i.e., the panel is cointegrated as a whole. The other pair of tests, called the group-mean tests, does not require $\varphi_{i}$ to be homogenous (and thus cointegrated) for all cross-sectional units of the panel and assumes that at least one unit is cointegrated.

Panel Statistics: $H_{0}: \varphi_{i}=0$ against $H_{1}: \varphi_{i}<0 \forall i$ 
Group Statistics: $H_{0}: \varphi_{i}=0$ against $H_{1}: \varphi_{i}<0$ for at least one $i$

\section{Results from Panel Error Correction Model}

Prior to estimating the Westerlund's PECM, it is important to seek statistical evidence on the presence of cross-sectional dependence amongst panel entities. Cross-sectional independence is an important assumption of panel cointegration models. This assumption necessitates the independence of errors across the different cross-sections of the panel. The issue of cross-sectional dependence is likely to occur in regional panel studies. This is because if the regional states are affected by common economic shocks, this may result in contemporaneous correlations i.e., cross-sectional dependence amongst the entities (cross-sections) included in the panel. Owing to the fact that the size of the panel unit root tests is sensitive to the presence of cross-sectional dependence, the testing of this assumption serves the purpose of identification rather than bringing in any descriptive accuracy.

We test the cross-sectional independence amongst panel countries for each of the individual model variables using the Pesaran CrossSectional Dependence test (CD). The method tests for the contemporaneous correlations in individual panel regression errors under the null hypothesis of zero covariance between errors.

$$
\begin{aligned}
& H_{0}=\omega_{i j}=\omega_{j i}=\operatorname{Cov}\left(\varepsilon_{i t}, \varepsilon_{j t}\right)=0, \forall t, i \neq j \\
& H_{1}=\omega_{i j}=\omega_{j i}=\operatorname{Cov}\left(\varepsilon_{i t}, \varepsilon_{j t}\right) \neq 0, \forall t, i \neq j
\end{aligned}
$$

Amongst all other tests popular for the identification of crosssectional dependence, the Pesaran CD test is regarded to be most robust for both stationary and non-stationary panels in addition to its small sample properties. The test is fairly consistent against single and/or multiple structural breaks in slope coefficients of panel regression and the error variance of individual regressions.

Table 3 contains the test statistics for Pesaran (2004) CD test. Except for R\&D, the null hypothesis of cross-sectional dependence cannot be rejected for all model variables. On the contrary, R\&D displays somewhat different results and does not reject the null hypothesis (up to a 7 percent level of statistical significance). Nevertheless, there is enough evidence in favor of cross-sectional dependence and thus the errors from panel 
regression tend to be contemporaneously correlated across the crosssections of the panel.

Table 3: Pesaran (2004) Pre-Estimation Test Results for Cross-Sectional Independence ${ }^{5}$

\begin{tabular}{lcccc}
\hline & $\begin{array}{c}\text { CD-Test } \\
\text { Statistics }\end{array}$ & p-value & $\begin{array}{c}\text { Average } \\
\text { Correlation } \\
\text { Coefficient }\end{array}$ & $\begin{array}{c}\text { Absolute } \\
\text { Correlation } \\
\text { Coefficient }\end{array}$ \\
\hline Domestic Productivity & 15.37 & 0.00 & 0.865 & 0.865 \\
RED & 1.80 & 0.07 & 0.112 & 0.586 \\
Human Capital & 4.02 & 0.00 & 0.232 & 0.723 \\
International Trade & 17.67 & 0.00 & 0.991 & 0.991 \\
Productivity Differential & 9.66 & 0.00 & 0.552 & 0.729 \\
\hline
\end{tabular}

Note: The Pesaran (2004) CD test is distributed standard normal and is estimated through the Stata routine $x t c d$.

With statistical evidence on the non-stationarity of all panel series, the next step is to estimate the (plausible) long-run linear cointegrating relationship between domestic productivity and model regressors using Westerlund's panel error correction model. The test estimates are found to be sensitive to the choice of deterministic regressors, leads, lags and the width of Bertlett kernel window (Abdullah et al., 2017; Burret et al., 2014). For this reason, the test is conducted under three different specifications in error correction relation: i) no deterministic regressors, ii) constant only, and iii) constant and trend. Also, cointegration is established under both unrestricted and restricted approaches, relative to the choice of leads and lags. The unrestricted case allows for automatic selection of optimal lags and leads through Akaike Information Criterion (AIC), allowing for a maximum of $1 \mathrm{lag}$, thus imposing no uniformity on short-run model dynamics. Under the restricted case, a single lead and lag is permissible, thus assuming uniform short-run dynamics for all the panel series. For both specifications, a (relatively) shorter kernel window of width 2 is chosen, owing to small data set ( $\mathrm{T}$ is ranging from 29 to 33). Since crosssectional dependence has been established by the Pesaran (2004) CD test, the test is run under bootstrapping sampling method, allowing for 400 reestimations of each cointegration test.

\footnotetext{
${ }^{5}$ In the previous section, Hong Kong and Malaysia were dropped out of time-series estimation of ECM. However, both countries are included in the panel data estimations.
} 


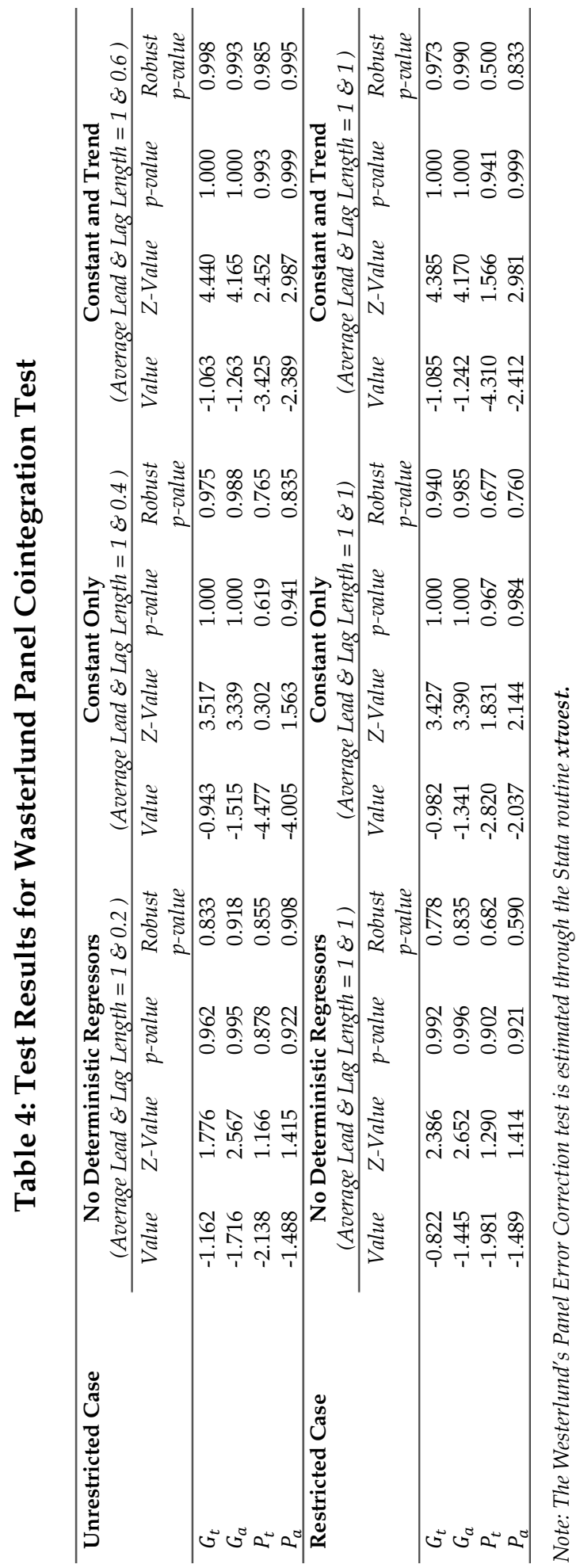


The sole purpose of such an extensive empirical practice is to obtain robust $\mathrm{p}$-values for our test statistics, which would be hindered by the significant cross-correlations (dependence) amongst the panel entities.

The panel ECM results are reported in Table 4. Starting with the unrestricted case, the null hypothesis of no cointegration cannot be rejected at any meaningful statistical significance. This is true for all three model specifications, varying with respect to the inclusion of deterministic regressors in the cointegration equation. As decided by AIC, for all model specifications, the AIC always picks a lead of value 1 and lags less than 1 (between 0 and 1). There is strong evidence of no valid long run comovement between panel series, irrespective of panel or group test estimates.

Looking at the test results of the restricted case of panel ECM yields results that are no different. The alternative hypothesis of a valid error correction process is again rejected at a high level of statistical significance (both for the whole integrated panel as well as for the cointegration of at least one cross-sectional unit). These findings are not supported by our time-series error correction test estimates, suggesting substantially high and statistically significant error correction adjustments of home productivity from short-run misalignments towards long-run equilibrium. Moreover, our estimates confirm the results yielded through many earlier and recent studies on regional income (productivity) catch up for East and South East Asian economies, advocating either absolutely no or conditional convergence to their intra- and ex-regional trading partners (Chowdhury \& Mallik, 2011; Haider et al., 2010; Masron \& Yusop, 2008; Zhao \& Serieux, 2019)

\section{Are the Panel Estimates Robust?}

The results yielded through panel ECM are suprising and contradict those of the earlier time-series ECM estimates, which had suggested convergence. To gather additional evidence, we employ another two panel data estimators: (i) Pedroni residual based test of cointegration, efficient against the problem of cross-sectional dependence in panels, and (ii) FisherJohansen combined maximum likelihood based rank test of cointegration.

\section{Pedroni Residual Based Test of Cointegration}

Pedroni's (1999) heterogeneous panel cointegration test allows cross-sectional interdependence with individual effects. Provided the data series are unit root in levels, that is, I(1), the Pedroni residual-based cointegration test is an extensively used tool to investigate if a long-run 
cointegrating association exists between model variables. The following time series panel formulation is proposed by Pedroni:

$$
\begin{aligned}
& q_{H i, t}=\alpha_{i}+\gamma_{i t} t+\beta_{i} X_{H i, t-1}+\varepsilon_{i t} \\
& \hat{\varepsilon}_{i t}=\sigma_{i} \hat{\varepsilon}_{i t-1}+\mu_{i t}
\end{aligned}
$$

Here $i=1, \ldots \ldots \ldots, N$ identifies the panels and $t=1, \ldots \ldots \ldots, T$ represents time periods. The parameters $\alpha_{i}$ and $\gamma_{i t} t$ are responsible for capturing country-specific effects and deterministic trend effects, respectively. $\hat{\varepsilon}_{i t}$ represents the calculated residual deviations from the long-run association between rer and $\tilde{a}$. In order to test the null hypothesis of "no cointegration" in a panel, that is, $\sigma_{i}=1$, Pedroni developed test statistics with asymptotic and finite sample properties. The Pedroni model allows heterogeneity among every member of the panel. Not only this, the model also allows heterogeneity in long-run cointegrating vectors as well as long-run dynamics.

There are actually two sets of residual based tests in the Pedroni cointegration model,. The first set of tests consists of pooling the residuals obtained from within-group regressions. The statistics of the tests are standard, normal and asymptotically distributed. This first set of tests includes panel $v$-statistics, panel $-\rho$ statistics, panel PP-statistics (or tstatistics, non-parametric) and panel ADF-statistics (or t-statistics, parametric). The other group of tests are also standard, normal and asymptotically distributed, but unlike the first set of tests, these tests involve pooling the residuals between the groups. This set consists of group - $\rho$ statistics, group PP-statistics (or t-statistics, non-parametric) and group ADFstatistics (or t-statistics, parametric). All of these seven tests involve estimators that average the estimated coefficients of individual members of the panel. Each of these tests is capable of accommodating individual specific short-run dynamics, individual specific fixed effects and deterministic trends, and individual specific slope coefficients (Pedroni, 2004).

In the event of rejection of the null hypothesis by all seven tests, one may easily draw a conclusion. However, unfortunately, this does not often happen. One frequently confronts a situation where there is a mix of evidence. If this happens, there is a need to look for a test that will explain the power of the cointegration model. As elaborated by Pedroni (2004), in case of a sufficiently large panel, where the issue of size distortion is of little importance, panel $v$-statistics display the best power in comparison to the other six tests. The panel $v$-statistics is a one-sided test where the large 
positive values tend to reject the null hypothesis (Pedroni, 2004). On the other hand, in the case of very small sized panels, group - $\rho$ statistics are likely to reject the null hypothesis. One can be confident enough of the group - $\rho$ statistics as the tests are purposely built for smaller samples and they are regarded as the most conservative of all the seven tests. The rest of the five tests lie somewhere in between the two extreme cases of panel $v$-statistics and group - $\rho$ statistics. However, they have advantages over a range of large, medium or small sized samples. One noticeable characteristic is that other than panel $v$-statistics, the remaining six tests diverge to negative infinity, that is, the large negative values tend to reject the null hypothesis.

\section{Fisher-Johansen Combined Maximum Likelihood Based Estimator of Cointegration}

Fisher (1932) derived a combined test that uses the results of individual independent tests. Maddala and Wu (1999) use Fisher's result to propose an alternative approach to testing cointegration in panel data by combining tests from individual cross-sections to obtain a test statistic for the full panel. If $p_{i}$ is the $\mathrm{p}$-value from an individual cointegration test for cross-section $i$, then under the null hypothesis for the panel:

$$
-2 \sum_{i=1}^{N} \log (p i) \rightarrow \chi^{2}(2 N)
$$

Maddala and $\mathrm{Wu}$ proposed two statistics: the Fisher statistic from the trace test and the Fisher statistic from the Maximum Eigenvalue test. By default the $\chi^{2}$ value based on the MacKinnon-Haug-Michelis (1999) pvalue is used for Johansen's cointegration Trace test and Maximum Eigenvalue test. Following Johansen's Cointegration approach, cointegration requires the rank to be less than the number of variables in the long-run equation.

For the test, the valid cointegration between model parameters necessitates that the rank of the test, representing the number of cointegrating vectors, must meet the following condition:

$$
0<\operatorname{rank}(r)<n \text {, }
$$

where $n$ is the number of model parameters. If there are $n$ parameters and there are $n$ cointegrating vectors, then the panels are likely to be stationary in levels, hindering the establishment of reliable a long-run cointegrating relationship. 


\section{Results from Two Panel Cointegration Estimators}

The upper panel of Table 5 displays the test results for the Pedroni residual based cointegration test. The test requires incorporating an appropriate number of lag(s) for each cross-section. The lag length selection is done through panel VAR, using the Schwarz Information Criterion (SIC). SIC suggests two lags to be included whilst estimating the cointegration model. Discussing the statistics obtained from Pedroni cointegration test, five out of the seven tests unanimously failed to reject the null hypothesis of no cointegration between productivity and its proposed determinants. The only exception are panel v-statistics and group PP statistics, suggesting cointegration between model parameters at five and ten percent statistical significance, respectively. However, on part of panel $v$-statistics, which tends to reject the null hypothesis, the evidence yielded is of trivial importance as the test is best suited for sufficiently large panels, a feature nonexistent for our sample data. Given that 5 of the 7 tests fail to reject the null of no cointegration, the test results should be interpreted in favor of nonexistence of productivity convergence between Japan and its middle- and low income neighbors. These results are in line with those obtained through Panel ECM estimated in the preceding section of the paper.

As regarding the test results obtained from the Fisher-Johansen panel cointegration test, similar to the Pedroni cointegration test, the results are once again not supportive of a valid long-run association between the model variables. However, the empirical evidence generated in this respect are of a different nature. Similar to the Pedroni cointegration estimator, this test also involves the inclusion of an appropriate number of lag(s) in estimation. Once again following the suggestion of SIC, the test is estimated using two lags of each model variable. The specification of deterministic regressors in the Johansen test is very important. EViews allows five specifications of deterministic regressors. We choose to employ specifications 3 and 4 of the test as these allow a reasonable degree of generality in incorporating trending behavior in the data. Thus, the existence/nonexistence of cointegration between productivity and its longrun determinants will be decided on the test results of Case 3 and Case 4. 
Table 5: Summary of Test Results for Pedroni Cointegration and Fisher Johansen Combined Cointegration Estimators

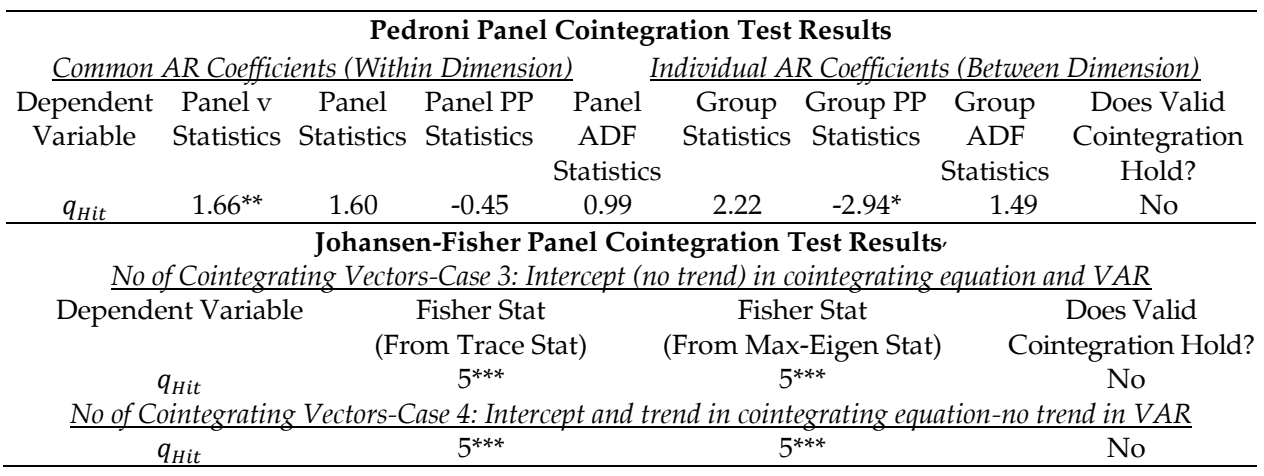

The Trace and the Maximum Eigenvalue statistics of both specification 3 and 4 of the test found no evidence of a valid cointegrating vector for the estimated model. The two test statistics under both test specifications commonly produce a rank of 5, implying that the rank of the test (number of cointegrating vectors, $r$ ) is exactly equal to the number of model variables $(n)$. These results challenge the panel unit root test findings, proving the model variables to be integrated of order 1 . Thus, parallel to the panel ECM and Pedroni cointegration tests findings, the Fisher-Johansen panel cointegration test could also not find a statistically significant long-run association between the productivity growth of Japan and the growth in its regional neighbors.

\section{Conclusion}

Regional economic linkages between countries aim to reduce income disparities and promote inclusive growth. The economic cooperation between East Asian countries under the ASEAN agreement is considered to be one of the finest examples of successful regional economic integration. However, in terms of region-wide productivity growth spillovers, the degree of inclusivity of this regional cooperation has always remained in question.

Following the footsteps of Cameron et al. (2005) and Kutan and Yigit (2009), the productivity convergence of low- and middle-income East Asian countries towards their rich neighbor(s) is modelled against their national levels of innovation, technology spillovers from the regional economic leader and their productivity differential with the frontier country. Overall, we find no significant productivity convergence in East 
Asia. Japan doesn not serve as the regional productivity growth driver for its poorer neighbor states.

Initially the study empirically had verified the above stated channels of regional productivity convergence for each country individually, using a time-series econometric estimator. Under the error correction representation, the per period speed of productivity convergence of five low- and middle-income regional states (towards Japan) was found highly significant as well as substantial. In each period, the productivity convergence is occurring at an abnormally high speed, ranging from 69 percent (Thailand) to 204 percent (Singapore) annually. However, of these results were not robust. This discrepancy can be attributed towards the small size of the study sample for each country, since the error correction model like many other time-series estimators is deemed asymptotically efficient (Engle \& Granger, 1987). In order to address this, we re-estimated the regional productivity convergence model using a panel data estimator. Based on structural dynamics (rather than a residual-based approach), Westerlund's (2007) restricted panel error correction estimator of long-run cointegration is used, investigating the (plausible) presence of productivity convergence for a panel of the seven East Asian countries. The results yielded contradicted those earlier obtained from the error correction model, suggesting no valid long-run association between the productivity of low-and middle income regional economies with that of Japan. These latter findings are robust to two different versions of Wasterlund's estimator (subject to the selection of leads and lags), each version offering three different variants (based on deterministic regressors included in the model). Thus, contrary to the initial time-series test findings, the panel data estimates strongly reject productivity catch up between low income East Asian states and Japan.

To confirm the panel finding of no convergence, we test it further through (a) Pedroni residual-based model of panel data cointegration and, (b) Fisher-Johansen combined maximum likelihood-based estimator of panel cointegration. These two estimators also support the findings of Wasterlund's panel error correction test results, confirming the lack of productivity convergence for East Asia.

Nevertheless, the empirical model estimated in this paper is limited in the sense that it does not take into account inter-country disparities pertaining to organizational and institutional capacities, which may plausibly explain productivity convergence channels in a more pronounced way. This may be taken as a future line of research. 
Differentiated levels of productivity can largely be attributed to heterogeneity, typically present in the form of technical efficiency and disparities in organizational and institutional capacities, hampering crossborder commodity trade, labor mobility and knowledge transfer. It is therefore critically important to control for these factors, while gauging growth performance of developing and transition economies. In addition to making regional economy less prone to global macroeconomic shocks, policies should be directed to eradicate technical and institutional disparities existing among regional member states. Investments that eliminate structural rigidities and the barriers to inter-country factor mobility may induce greater speeds of productivity convergence, particularly for middle- and low-income regional players. 


\section{References}

Abdullah, S., Siddiqua, S., \& Huque, R. (2017). Is health care a necessary or luxury product for Asian countries? An answer using panel approach. Health Economics Review, 7(1), 4.

Aghion, P., Howitt, P., Brant-Collett, M., \& García-Peñalosa, C. (1998). Endogenous growth theory: MIT press.

Asian Development Bank. (2016). Asian Development Outlook 2016: Asia's Potential Growth.

Aubyn, Miguel S. (1999). Convergence across Industrialised Countries (1890-1989): New Results using Time-Series Methods. Empirical Economics, 24(1), 23-44.

Baumol, W. J. (1986). Productivity Growth, Convergence, and Welfare: What the Long-Run Data Show. The American Economic Review, 1072-1085.

Ben-David, D., \& Loewy, M. B. (1998). Free Trade, Growth, and Convergence. Journal of Economic Growth, 3(2), 143-170.

Bernard, A. B., \& Jones, C. I. (1996a). Comparing Apples to Oranges: Productivity Convergence and Measurement Across Industries and Countries. The American Economic Review, 1216-1238.

Bernard, A. B., \& Jones, C. I. (1996b). Productivity across Industries and Countries: Time-Series Theory and Evidence. The Review of Economics and Statistics, 135-146.

Burret, H. T., Feld, L. P., \& Köhler, E. A. (2014). Panel Cointegration Tests on the Fiscal Sustainability of German Laender.

Cameron, G., Proudman, J., \& Redding, S. (2005). Technological Convergence, R\&D, Trade and Productivity Growth. European Economic Review, 49(3), 775-807.

Chowdhury, K., \& Mallik, G. (2011). Pairwise output convergence in selected countries of East Asia and the Pacific: an application of Stochastic Unit Root test. ASEAN Economic Bulletin, 1-15. 
Cincera, M. (2005). Firms' Productivity Growth and R\&D Spillovers: An Analysis of Alternative Technological Proximity Measures. Economics of Innovation and New Technology, 14(8), 657-682.

Coe, D. T., \& Helpman, E. (1995). International R\&D Spillovers. European Economic Review, 39(5), 859-887.

Coe, D. T., Helpman, E., \& Hoffmaister, A. W. (2009). International R\&D spillovers and institutions. European Economic Review, 53(7), 723741.

Pleijt, A. M. (2018). Human Capital Formation in the Long Run: Evidence from Average Years of Schooling in England, 1300-1900. Cliometrica, 12(1), 99-126.

Engle, R. F., \& Granger, C. W. (1987). Co-integration and Error Correction: Representation, Estimation, and Testing. Econometrica: Journal of the Econometric Society, 251-276.

Franks, J. R., Barkbu, B., Blavy, R., Oman, W., \& Schoelermann, H. (2018). Economic Convergence in the Euro Area: Coming together or Drifting Apart? IMF Working Paper WP/18/10.

Fukuda, S.-i., \& Toya, H. (1995). Conditional Convergence in East Asian Countries: The Role of Exports in Economic Growth. Growth Theories in Light of the East Asian Experience, NBER-EASE Volume 4 (pp. 247-265): University of Chicago Press.

Gräbner, C., Heimberger, P., Kapeller, J., \& Schütz, B. (2019). Structural Change in Times of Increasing Openness: Assessing Path Dependency in European Economic Integration. Journal of Evolutionary Economics, 1-29.

Giles, D. E. (2005). Output Convergence and International Trade: TimeSeries and Fuzzy Clustering Evidence for New Zealand and Her Trading Partners, 1950-1992. The Journal of International Trade $\mathcal{E}$ Economic Development, 14(1), 93-114.

Griffith, R., Redding, S., \& Reenen, J. V. (2004). Mapping the Two Faces of R\&D: Productivity Growth in a Panel of OECD Industries. Review of Economics and Statistics, 86(4), 883-895. 
Griliches, Z., \& Lichtenberg, F. R. (1984). R\&D and Productivity Growth at the Industry Level: Is there Still a Relationship? RED, Patents, and Productivity (pp. 465-502): University of Chicago Press.

Haider, A., Hameed, S., \& Wajid, A. (2010). Income Convergence Hypothesis: A Regional Comparison of selected East and South Asian Economies.

Hsiao, F. S., \& Hsiao, M. C. W. (2004). Catching Up and Convergence: Long-run Growth in East Asia. Review of Development Economics, $8(2), 223-236$.

Kang, L., \& Peng, F. (2018). Economic Reform and Productivity Convergence in China. Arthaniti: Journal of Economic Theory and Practice, 17(1), 50-82.

Kasman, S., Kasman, A., \& Gökalp, G. (2019). Efficiency and Productivity Convergence in Health Care Systems: Evidence from EU Member Countries. METU Studies in Development, 46(2), 227-250.

Khaemba, B. W. (2014). Relationship between Education Financing and Human Capital Investment: A Survey of Public Secondary Schools in Kimilili-Bungoma Sub-County. International Journal of Academic Research in Business and Social Sciences, 4(4), 148.

Kutan, A. M., \& Yigit, T. M. (2009). European Integration, Productivity Growth and Real Convergence: Evidence from the New Member States. Economic Systems, 33(2), 127-137.

Lawrence, R. Z., \& Weinstein, D. E. (2001). Trade and Growth: Import-Led or Export-Led? Evidence from Japan and Korea. Rethinking the East Asian Miracle, 379-408.

Lim, L. K., \& McAleer, M. (2000). Convergence and Catching Up in SouthEast Asia: A Comparative Analysis. Paper presented at the Econometric Society World Congress.

Lluís Carrion-I-Silvestre, J., \& German-Soto, V. (2007). Stochastic Convergence amongst Mexican States. Regional Studies, 41(4), 531541. 
Maddala, G. S., \& Wu, S. (1999). A Comparative Study of Unit Root Tests with Panel Data and a New Simple Test. Oxford Bulletin of Economics and statistics, 61(S1), 631-652.

Mahmood, A., \& Talat, A. (2008). Total Factor Productivity Growth in East Asia: A Two Pronged Approach. European Journal of Economics, Finance and Administrative Sciences, 14(14), 93-111.

Masron, T. A., \& Yusop, Z. (2008). AFTA, income growth, and income convergence in ASEAN. The International Trade Journal, 22(3), 290314 .

Michelis, L., \& Neaime, S. (2004). Income Convergence in the Asia-Pacific Region. Journal of Economic Integration, 470-498.

Mutaqin, Z., \& Ichihashi, M. (2012). Real Convergence in ASEAN and the Eurozone: Demographic and Maastricht Criteria Roles. Paper presented at the Proceedings $2^{\text {nd }}$ International Conference on Economics, Trade and Development.

Pedroni, P. (1999). Critical Values for Cointegration Tests in Heterogeneous Panels with Multiple Regressors. Oxford Bulletin of Economics and statistics, 61(S1), 653-670.

Pedroni, P. (2004). Panel Cointegration: Asymptotic and Finite Sample Properties of Pooled Time-Series Tests with an Application to the PPP Hypothesis. Econometric theory, 20(3), 597-625.

Persyn, D., \& Westerlund, J. (2008). Error-Correction-based Cointegration Tests for Panel Data. Stata Journal, 8(2), 232-241.

Quintana-Romero, L., Correa-Quezada, R., Ramón-Mendieta, M. G., \& Álvarez-García, J. (2019). Sectoral Regional Growth and Convergence in Ecuador: An Analysis of the Intra-Distributive Dynamics of Productivity. Symmetry, 11(4), 461.

Schultz, T. W. (1960). Capital Formation by Education. Journal of Political Economy, 68(6), 571-583.

Solarin, S. A., Ahmed, E. M., \& Dahalan, J. (2014). Income Convergence Dynamics in ASEAN and SAARC Blocs. New Zealand Economic Papers, 48(3), 285-300. 
Terleckyj, N. E. (1980). What Do R\&D Numbers Tell Us about Technological Change?. The American Economic Review, 70(2), 55-61.

Vâlsan, C., \& Druică, E. (2020). Corporate Performance and Economic Convergence between Europe and the U.S.: A Cluster Analysis along Industry Lines. Mathematics, 8(3), 451.

Westerlund, J. (2007). Testing for Error Correction in Panel Data. Oxford Bulletin of Economics and statistics, 69(6), 709-748.

Wooldridge, J. M. (2015). Introductory Econometrics: A Modern Approach: Nelson Education.

Xu, B. (2000). Multinational Enterprises, Technology Diffusion, and Host Country Productivity Growth. Journal of Development Economics, 62(2), 477-493.

Yasar, M., \& Morrison Paul, C. J. (2008). Foreign technology transfer and productivity: Evidence from a matched sample. Journal of Business $\mathcal{E}$ Economic Statistics, 26(1), 105-112.

Zachariadis, M. (2003). R\&D, Innovation, and Technological Progress: A Test of the Schumpeterian Framework without Scale Effects. Canadian Journal of Economics/Revue canadienne d'économique, 36(3), 566-586.

Zhang, Z. (2001). Trade Liberalization, Economic Growth and Convergence: Evidence from East Asian Economies. Journal of Economic Integration, 147-164.

Zhao, J., \& Serieux, J. (2019). Globalization, Regionalization and Convergence in East Asia. The Journal of International Trade $\mathcal{E}$ Economic Development, 28(4), 486-507. 